\title{
Integration of EBSCO Discovery Service widget into the learning spaces of LMS
}

\section{A case study of Wawasan Open University}

\author{
Bee Leng Chew \\ Tun Dr Lim Chong Eu Library, \\ Wawasan Open University, Penang, Malaysia \\ Marnisya Abdul Rahim \\ Department of Educational Technology and Publishing Unit, \\ Wawasan Open University, Penang, Malaysia, and \\ Vighnarajah \\ Faculty of Social Sciences and Liberal Arts, UCSI University, \\ Kuala Lumpur, Malaysia
}

\begin{abstract}
Purpose - Recent advancement in technological development has encouraged distance learning institutions to be more productive and creative in effectively utilizing the Learning Management System (LMS). Among the many measures employed is the integration of federated search engine into the LMS which allows for a more productive and wider scope of information retrieval through the provisions of library resources and services. The purpose of this paper is to report one such case study in Wawasan Open University exploring the integration of federated search engine (EBSCO Discovery Service (EDS) widget) into the learning spaces of LMS. Widgets resemble apps that enable the integration of EDS functionality in providing access for students to retrieve library learning resources from the convenience of the LMS, excluding the need to log onto the library. Design/methodology/approach - This paper presents a discussion that highlights the development and conjectural implementation of a framework on the integration of the EDS widget into the University's LMS. Data collection includes meta-analysis data from the micro- and macro-level infrastructure that make up the framework, namely, end-user layer, system layer and data management layer.

Findings - Findings from this study addressed significant importance to the library in promoting effective search and utilization of information needs. The findings will also make clear recommendations in developing effective collaborations between the library and faculties. Although the implementation of this framework is still in a developmental stage, this study still provides pertinent information in validating the integration of EDS into the University's LMS.

Research limitations/implications - While serious limitations are not anticipated, possible concerns do exist with programming algorithms in the integration of EDS into the LMS. These challenges will be reported in the paper as reference for future replications of study

Practical implications - One key implication is the increase in the usage of the library resources and the potential to reach a larger audience of remote library users.

Originality/value - The primary advantage is to minimize the need for multiple gateway login while ensuring the library to monitor relevant library databases activities throughout the system check of the LMS.

Keywords MOODLE, EDS, Library resources, Learning spaces, Federated search engine tool,

Learning management system

Paper type Research paper

(c) Bee Leng Chew, Marnisya Abdul Rahim and Vighnarajah. Published in the Asian Association of Open Universities Journal. Published by Emerald Publishing Limited. This article is published under the Creative Commons Attribution (CC BY 4.0) licence. Anyone may reproduce, distribute, translate and create derivative works of this article (for both commercial and non-commercial purposes), subject to full attribution to the original publication and authors. The full terms of this licence may be seen at $\mathrm{http} / / /$ creativecommons.org/licences/by/4.0/legalcode
\end{abstract}

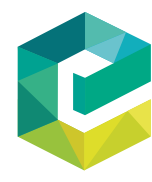

Asian Association of Open Universities Journal Vol. 12 No. 2, 2017 pp. $137-153$ Emerald Publishing Limited 2414-6994 DOI 10.1108/AAOUJ-01-2017-0013 
AAOUJ

12,2

138

\section{Introduction}

E-learning has emerged as a serious contender to help support the learning needs of individuals. New tools and approaches are in demand to address new learning demands of university and lifelong education (Klopfer, 2008). However, effective adoption of learning management system (LMS) is a challenge for many higher education institutions (HEIs) even in the era of rapid e-learning advancement. Proper planning and development of LMS allows for the LMS to act as a one-stop service for the students, rather than having to visit multiple sites to access different sets of materials (Sarvi and Pillay, 2015).

The LMS system at Wawasan Open University (WOU) uses MOODLE, and is managed by the Educational Technology and Publishing Unit. The library sits organizationally separate with a reporting line to the Chancellery, though both units play the role of academic support to students and academic faculties. WOU, being a distance learning institution, has study centers (apart from the main campus in Penang) in four geographically different locations - Ipoh, Perak, Johor Bahru, Johor, Kuala Lumpur and Kuching, Sarawak. The library located in each of these study centers employs one administrative support staff who overlooks the overall operation of the library, with guidance and facilitation from the library in the main campus (Penang).

Conduct of information literacy instruction classes is not an easy task for distance learning institutions. Despite the library's efforts in periodically organizing such classes, majority of distance learners are not able to attend due to their busy schedules and are stalled with traffic in different geographical areas. With each passing day, the library loses its' image and visibility among the distance learners, and this gives rise to serious concern on part of the library. Moreover, the library visibility is not promoted because librarians have no direct, active collaboration with the distance learners and academic faculties, either in managing the LMS or in facilitating the distance learners' coursework, assessment and learning process. Hence, it is important for the library to capitalize on a new learning space to increase its visibility and to strengthen its role in the University.

On the current student portal, there is only a universal library section tab which simply offers a link to the library's homepage website (http://woulibrary.wou.edu.my). The user starts to search for scholarly information from the two search engines provided, one is the Virtua Online Public Access Catalog (OPAC), and the other is the EBSCO Discovery Service (EDS).

In the rapid expansion of the digital environment, it is evident that the gap of accessibility between e-learning platforms (referring to the LMS in the context of this study) and library system has increased. This raises concern that the library system will face serious risks of marginalization if relevant measures are not taken to integrate the library system in the e-learning platform (Kampa, 2017).

EBSCO (2016a) affirms that EDS is an environment that provide users with rich search experience by incorporating relevant resources into an effective interface - "Tailoring the experience to meet your institution's needs, and monitoring those needs over time, is essential to obtaining maximum value." The following widget examples were taken from EBSCO's (2016a) document on EDS best practices guide - customization:

- Custom Survey App (widget): this simple app allows library staff to prompt users to take a survey. Initiating the survey can either launch a new browser tab, or launch the survey in a new browser window. The app can link to any web-based survey.

- LibGuides App (widget): this widget, also called Subject Guides or Research Guides, are librarian-created web pages that list recommended resources for finding information - such as databases, journals, books and websites - that are relevant to a patron's area of study. A LibGuides App (Figure 1) will allow you to direct your user to these important resources.

- Ask-A-Librarian App (widget): provides virtual reference assistance to your users with an Ask-A-Librarian chat window (Figure 2). 


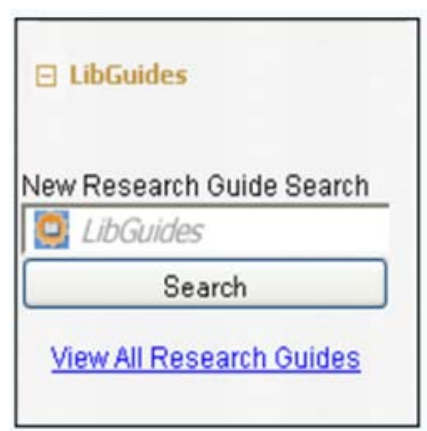

EDS widget

Source: EBSCO (2016a)

Figure 1.

LibGuides

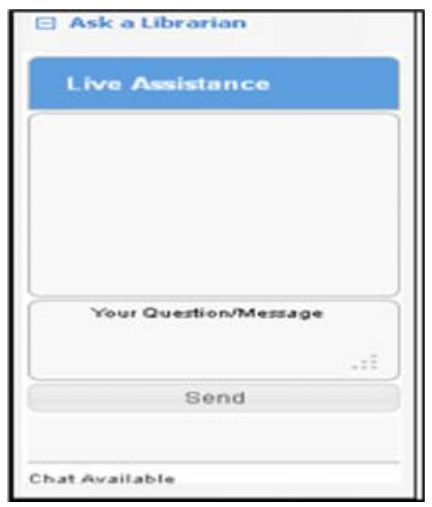

Source: EBSCO (2016a)

Figure 2. Ask-A-Librarian

\section{Need for this study}

The need for this study was well summarized by Pareek and Gangrade (2016, p. 14): "Libraries and information centers are witnessing new paradigm shifts."

They further highlighted how the following factors (p. 14) motivate this paradigm shift:

- transition of information sources and systems from paper to electronic media;

- complexity in information needs of highly demanding clientele;

- increase in the cost and quality of information; and

- information technology has introduced many changes in the way information is identified, procured, processed and disseminated to library clientele.

These factors can be traced back almost two decades ago when digital revolution addressed emergence of librarians as information technology educationalist and a growing means of accessing the library other than the desktop computer (Bazillion, 2001). Several years later, these aspects were highlighted again, giving further emphasis to librarian as instructor, as well as collaboration between the library and faculty (Schulte, 2008). Evidently, academic libraries are changing from being a provider of information resources to that of a facilitator and activists in the business of knowledge acquisitions by users in learning, teaching and 
AAOUJ

12,2

140

research activities. Today, learners are using a wide range of information beyond what is provided by library (Fatt and $\mathrm{Su}, 2016$ ), and this attests to the need for the library to keep abreast with technology, especially in the field of library and information science in a globalized world. One such initiative would be to explore the integration of federated search engine, namely, the EDS widget, into the learning spaces of the university LMS. In fact, this widget is a critical product for academic libraries in managing complex, multi-format collections, and this approach jives with universities increasing investments in electronic resources (Breeding, 2017, p. 30).

This measure brings about several significances. First, a common concern on the usage of the library's subscribed digital resources is the poor utilization by users, usually with varied reasons. Doiron and Asselin (2011) strongly recommended for librarians to create provision of dynamic and integrated systems of delivery of resources to overcome this concern. Second, there are a few common challenges faced by the library in managing the traditional automated integrated library system (ILS) and its printed collections. When electronic resources continue to steadily replace the print in many collection areas, this creates changes in the workflow of access to resources for library patrons. Budget management is affected as well. Subscribed electronic resources from multiple vendors still need to be closely integrated with the library automated systems to facilitate easier discovery and access for patrons.

Third, access and familiarity with automated library system has always proved to be a challenge for adult learners, especially more for those enrolled in distance learning institutions such as Wawasan Open University. At this juncture, it is important to acknowledge that adult learners are returning to learning after a number of years committing to other aspects of their lives, and such these endeavors of interacting with the library would definitely not take precedence in their learning process. Such situations have been observed by the authors on repeated occasions on various levels of interactions - library, educational technology publishing unit as well as faculty. Without prompt actions to recognize these concerns, it is very likely for the adult learners to turn away from learning and be disheartened with the entire university learning experience (Behr and LaDell-Thomas, 2014). Finally, the benefits of this widget integration can be seen as it empowers the librarian to suggest more valuable reading lists, important books or journals in its subscribed databases. Such integration also allows better avenues for librarians to collaborate with faculties and relevant stakeholders - permitting for a more materialized presence of the library, instead of the conservative view of the library offering nothing more than collection of books and physical space.

\section{Research objectives}

The purpose of this study was to explore the integration of federated search engine into the learning spaces of the University's LMS. Following were the specific objectives of this study:

(1) to explore the integration of the EDS widget into the University's LMS;

(2) to develop a framework that represents the integration of the EDS widget into the University's LMS; and

(3) to explore the challenges faced in the integration of the EDS widget into the University's LMS.

\section{Literature review}

Academic libraries, especially those operating in the open and distance e-learning environment, have a critical role to play as data provider for both on-campus and offcampus students. Acknowledging these needs, initiatives are always attempted by these libraries to fashion more productive and wider scope of information retrieval through the provisions of library resources and services. 
According to Renauld et al. (2015), many academic libraries have experienced sharp decline in the number of books that circulate from their collections. Circulation patterns have changed over time. This challenges the assumption that users are no longer interested in library resources (print and digital). Another general observation is that there is no queue at the circulation desk, a measure of library value.

The new generation of library services platform aims to manage a broader representation of library collections including electronic and digital material in addition to print - since the ILS only manages a portion of library's materials. Research reports, such as from Online Computer Library Center and Library of Congress have documented what many librarians already knew that library webpage and catalog were no longer the first choice to search for information (Owen and Michalak, 2015).

In fact, Andrew (2013) highlights an attempt by Sheffield Hallam University on embarking on review of next-generation library management system. In that attempt, Andrew examines the growing interest in federated search in next-generation library management systems. He asserts that (p. 2):

As electronic resources began to grow as a proportion of collections, traditional OPACs became more limited as a means of directing users to the resources they required. Federated search, searching across a number of discrete databases from a single interface, became popular around the millennium but was only partially successful. Cross-searching databases with differently structured metadata produced patchy and incomplete results. Federated search may have been most useful in highlighting to the user which databases to search.

Andrew further discusses how web-scale discovery services have emerged as an effective alternative to traditional OPACs practised five years ago:

Around 5 years ago, as libraries were finding that traditional OPACs were not able to guide users to non-print materials and articles and that federated search was not a satisfactory solution, 'web-scale' discovery services began to emerge, built around unified indexes of licensed scholarly publications combined with metadata for the local catalogue and other local content, with a Google-like simple search box, and a consolidated, single result list.

In light of such innovation in federated search, advent of technology has also given rise to effective integration of widgets into LMSs - a substantially victorious improvement in the field of library information search. According to Vaughan (2011), widgets refer to discretionary pieces of application that provide additional function to the site. Widgets, which can be integrated to the site using custom HTML code or an iframe URL, allow for linking or tagging external content to the interface. Vaughn cites, "Examples of widgets could include integration of other library tools, such as LibGuides subject guides and blogs. Other examples include Flickr image, Google Books, and Wikipedia search functionality widgets and incorporation of an online chat client, such as Meebo" (p. 6).

EBSCO draws attention to other examples of widgets, as follows (EBSCO, 2016a):

- Google Scholar.

- WorldCat Search.

- Flickr Photo Sharing.

- Goodreads Book Recommendations.

- Google Books.

- YouTube.

- LibGuides.

- Ask-A-Librarian.

- Custom survey. 
AAOUJ 12,2

Kowalik (2015) brings to attention an effort by Raynor Memorial Libraries to integrate a library widget into all course homepages in Desire2Learn, Marquette's Learning Management System: The widget, developed using HTML, CSS and jQuery, permits "students to search the EBSCO Discovery Service or MARQCAT, the traditional catalog, directly from within the LMS course site. Before the start of the Spring 2015 semester, Google Analytics and Google Tag Manager were incorporated into the widget. The code allows tracking the number of times links in the widget have been clicked, which classes have used the widget and terms searched for." Figure 3 below illustrates the anatomy of the Library widget for the campus LMS.

Leeder and Lonn (2014) have stressed that effective use of the LMS has been shown to improve the quality of teaching and learning and enriched the educational experiences of students. For academic libraries, incorporating library resources and services into the LMS offer the opportunities to improve library visibility, increase relevance with students and strengthen relationship with academic faculties (Tumbleson and Burke, 2013).

According to Black and Blankenship (2010), it is essential that library resources to be presented strategically in the LMS. This is especially true since students are course-centric in their work and library resources need to be presented to them in a convenient place. Farkas (2015) highlighted that librarians should examine how the LMS is used at its own institution, their internal technologies resources and ability to maintain a chosen embedded approach for the long term. Integration can be done at the macro or micro level of library involvement. The hurdle, however, is the willingness of the unit administering LMS to provide library the space and access to achieve integration. Norbury (2013) has also pointed that barriers still exist between learners and library resources, with the biggest barrier being the effective use of LMS, where majority of them still fail to provide an easy way to integrate library resources into course materials.

In the context of WOU distance learners, Vighnarajah and Santhiram (2014)'s qualitative study has also found that there is a poor engagement between distance learners with library services which can potentially lead to learners experiencing a sense of isolation in the overall university learning experience. This is supported by one of Vighnarajah et al. (2015) survey study findings which highlighted that 19 percent of the sample size (distance learners) were not able to locate information, while 12 percent of them were not aware that relevant information (printed or digital copies) were available in the library. They further recommended for the library to provide proper guidance to distance learners in searching for information.

Figure 3.

Anatomy of library widget
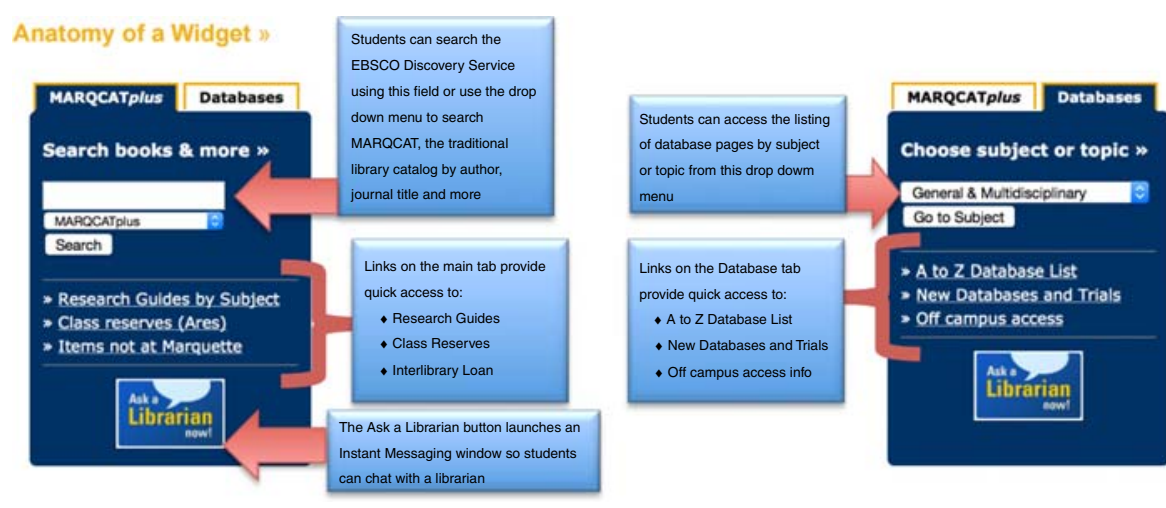

Source: Kowalik (2015) 
This recommendation syncs with the four pillars of the information commons philosophy in academic library service delivery, namely, connectivity, collaboration, creation of knowledge and community (Seal, 2015).

\section{Methodology framework}

Since LMS is a powerful tool which has wider acceptance in a higher educational institution, it can help facilitate learning and provide opportunities for students to collaborate interact and participate more actively. In general, the authors concur with Kampa (2017) that services and resources of the Library are noticeably missing from this e-learning environment - be it in the design, development and implementation. In light of this, provisions of embedded librarians in the spaces of the LMS could prove to be most beneficial (Tumbleson and Burke, 2013). They raised strong opinions that LMS embedded the librarian is becoming the primary and most productive method for connecting with students, considering that the students are constantly engaging in ubiquitous, mobile learning environment. This way, library resources and services can be more accessible to adult learners who grapple in obtaining relevant information in engaging in the learning. Such integration study at WOU is interdisciplinary across all faculties - promoting discovery service and use of library resources, and all the while, creating library visibility and impact to students and faculties.

A simple methodological approach was proposed to establish a service-oriented integration system between the EDS widget into the existing LMS to support accessibility of library resources. Possible micro- and macro-level learning spaces in the LMS were examined to determine the interoperability and technology used. Prior to that, necessary permissions were sought from the relevant academic faculties and LMS stakeholder. There were no restrictions from EBSCO vendor as to where the library can place the widget, as long as the access is limited to the WOU users.

Prior to the integration of the architecture setup, work was required on the EDS customization by the librarian to import its widget, customize the search box and customize links into the University's EDS platform. The EBSCOadmin website gave permission to add the widget either as iFrame URLs or custom HTML code, where the latter was chosen (EBSCO, 2016b). The creation of the customized search box with HTML code is done through the EDS search box builder tool where selection was done on one of the three available styles. The HTML code then can be embedded into the library's website or the LMS platform. Testings were carried out after the integration setup by the relevant stakeholders to ensure interoperability.

This framework advocates collaborative space between the library and LMS that acts as an avenue of knowledge and learning which ultimately aims to increase student activities. As a result, a web-service-oriented framework is proposed, providing a flexible integration model in which the library resources components were connected in the LMS as another gateway for users to access. The indicators used for future assessment are the access to the library resources using logins to the LMS and using gateway entry statistics from the EBSCOadmin tools.

\section{Findings and discussion}

The ensuing discussion highlights the findings of the study. Discussion will be presented following the stipulated research objectives to facilitate comprehension.

Research objective 1: to explore the integration of the EDS widget into the University's LMS This section presents the framework that highlights the development of the integration of EDS search engine widget into the LMS platform. Prior to that, a brief overview of each of the technologies related to this case study is presented, namely, the WOU's web-based LMS MOODLE version 2.5 and the library's subscribed EDS search engine widget. 
AAOUJ

12,2

144

\section{LMS - MOODLE}

MOODLE (an acronym for Modular Object Oriented Dynamic Learning Environment), developed in 2002, is an open source technology deemed as the world's most popular e-learning platform. It empowers students to manage their learning (Cooch, 2010). MOODLE is a modular system based on plug-ins, for different kinds of content and collaborative activities. It contains navigation block with a link to various site pages, profiles and courses (micro-level). At WOU, the LMS is a pivotal system that University students use to access their online and supplementary course materials. In addition, the platform creates a comprehensive learning experience to students as it supports collaborative learning community by offering multiple modes of learning from self-paced coursework via web links, downloadable audio and video contents to group learning (online forums). As part of the periodic update of the LMS system, the LMS's MOODLE has been upgraded to version 2.5. The current MOODLE is adaptable to all mobile devices which is the first step toward mobile technology with notable enhancements for its users.

MOODLE has the capability of tracking course activities. Detailed information known as logs records time, date, user's internet Protocol (IP) address and user activities are displayed in a report format. Using MOODLE, administrator and instructor are able to track the number of views for each course activity and the last time the activity was accessed. MOODLE reports and statistics has improved tremendously since MOODLE version 1.0; now the administrator and instructor are able to learn from these data on students' behavior on the course activities.

Figure 4 displays the library resources gateway in the LMS site which can be accessed by WOU's registered users, i.e. distance learners, academic staff and part-time tutors. The frequency of the LMS usage activity can be tracked, and the data cover logins, views and postings by different user groups as shown in Figure 5. As LMS forms a popular basis for e-learning and blended learning, the integration of the EDS widget into LMS helps to support and expand accessibility for library users.

By adding the HTML widget in the course on the LMS, WOU students are able to search for journals without ever logging out from their course resources. This new feature helps to

Figure 4.

Library gateway in the LMS

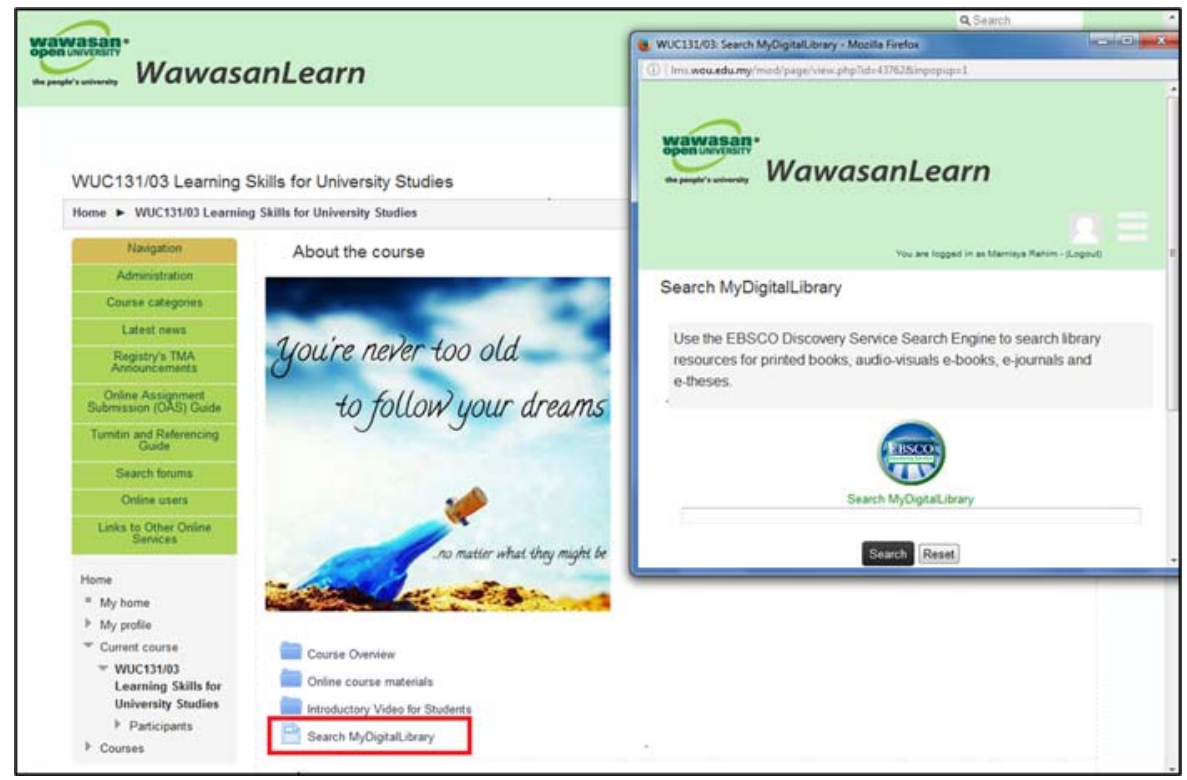




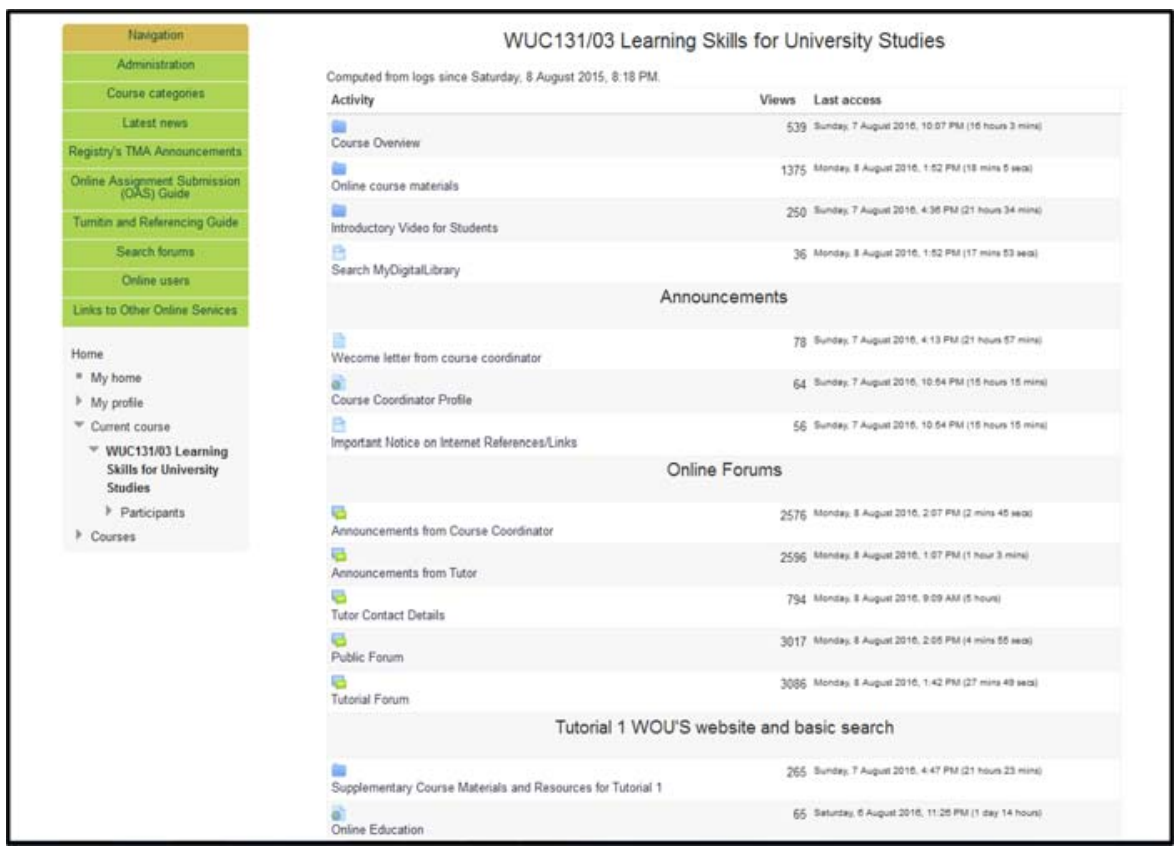

EDS widget

145

Figure 5.

LMS's activity report on the resources views and last accessed

promote the engagement and usage of LMS as well as the digital library. The major advantage of this feature is that our distance learners can minimize the time spent on searching information on the EDS.

\section{EDS widget}

Over the years, WOU Library has subscribed to several proprietary databases to cater the information resources needs of its users such as e-books, e-journals, e-references, e-news and e-theses from various academic disciplines. As searching platforms among these databases can be difficult, there is an urgent need to enable users' searching process to be less daunting and resources easier to find.

In January 2010, WOU Library subscribed to EBSCOHost Integrated Search (EHIS), a kind of library Google search engine tool, which allowed users to simultaneously search EBSCO databases as well as those from other subscribed databases, Virtua OPAC and other publishers' packages. The search engine tool provided a more powerful search experience for users. All the users need to do is to log in, then conduct an EHIS search and get results which include printed books, e-books, audio-visuals, open access articles and government documents in one list. Nevertheless, in February 2013, EHIS takes its integrated searching to a higher level through EDS by providing access to all of an institution's EBSCOHost and non-EBSCO resources.

A total of seven core databases were connected, as presented in Table I. The EDS provided a variety of tools to leverage resources and provide comprehensive reporting and analysis functionalities. EHIS complements EDS which extends the discovery experience to external sources that are not made available for local harvesting. This eliminated any possibilities of slow search results. The features and functionalities of EDS are as follows - basic and advanced search, subject facets, publication facets, sorting results by relevancy order, date slider limiter, personalized folder, custom links, inter-library loan (ILL) 
AAOUJ

12,2

146

Database/publisher

Content type

Description

Holdings

Online Public Access Printed books, perpetual

Catalog (Virtua OPAC) e-books, audio-visual

(Innovative Interfaces materials, media clippings,

Global Limited, Ireland) staff contributions, e-projects reports (post-graduate)

Books $24 \times 7$

E-book

(Skillsoft, USA)

This is the library web-based online

(volumes)

catalog for printed books, journals,

audio-visuals and e-resources owned

by the University and DISTED

College (sister institution) libraries

This database contains thousands of

reference books, reports and book

summaries on business, finance and

information technology disciplines

Ebrary E-book

(ProQuest LLC, USA)

This database provides thousands of

52,866

e-books from the world's leading

publishers on academic disciplines

EBSCOHost (EBSCO E-book and E-journal

This database provides world's

leading collection of journals

from scholarly business

database and computing and applied

sciences disciplines

JSTOR E-journal

This database provides back issues

of the core scholarly journals on arts

and sciences disciplines

Emerald Management E-journal

This database provides access to

high-quality peer-reviewed

(Emerald Group

management journals

Publishing, UK)

Table I.

ProQuest Dissertations E-theses

This database provides access to

and Theses Full-Text

List of databases

(ProQuest LLC, USA)

full-text dissertations on humanities

and social sciences disciplines

request and link source to increase efficiency of access which point directly to the material (EBSCO, 2012).

With the development of Google and other web-based search engines, library's catalog database which contains bibliographic information of collection is no longer an important research tool for users. Thus, it becomes increasingly important for librarians to sustain easy and fast access to library's holding (Owen and Michalak, 2015). Choy and Goh (2016) stressed that in the current time, academic library's information only occupy a small fraction of world information; hence, the librarian shoulders a critical role in facilitating students to be effective information users.

The above electronic resources were procured from commercial publishers under online or server-based licenses and are hosted on EZproxy server. EZproxy is a remote authentication software popular with academic libraries was developed by Chris Zagar, from his own company, Useful Utilities LLC, USA. According to Wikipedia (2016), EZproxy is a popular web proxy server that is widely used in academic libraries for providing off-campus access to their owned or subscribed electronic resources to ensure secure accesses, no illegal downloading or system intrusion. User activities are tracked and assessed through EZproxy log files.

Strategic technology products subscribed by academic libraries (such as the products cited above) represent some of the biggest investments libraries make. Libraries would definitely be interested to know how well these product function in its institution (Breeding, 2016). The most significant difference of integrating this widget in the LMS is that information about library large collections that have been scattered previously in different sites were integrated into a single point of information access. The OPAC capabilities are being enhanced and aligned in the search engine widget. As electronic 
resources have become an important percentage of library collections, the delivery of information to its users must be enhanced. The use of faceted and limiting browsing tools in this widget allowed users to limit the search records, filter by language and date of publication, for example.

Research objective 2: to develop a framework that represents the integration of the EDS widget into the University's LMS

This section highlights findings from the development of a framework that represents the integration architecture of the EDS widget into the University's LMS. Figure 6 illustrates the framework. The framework is made up of the end-user layer, system layer and data management layer.

\section{End-user layer}

This layer acts as a service layer which allowed end users to start searching their key terms either from the library website (http://woulibrary.wou.edu.my) or directly from the search engine widget integrated at LMS (Figure 7). It is a single-search interface to multiple resources. User can perform query, modify, edit, filter search results accordingly. Library generally can take a macro or micro-level approach to integrate EDS into the LMS. A macro-level approach delivers the same widget interface which demonstrates a library presence, and micro-level approach involves integration at individual courses (Black and Blankenship, 2010; Shank and Dewald, 2003).

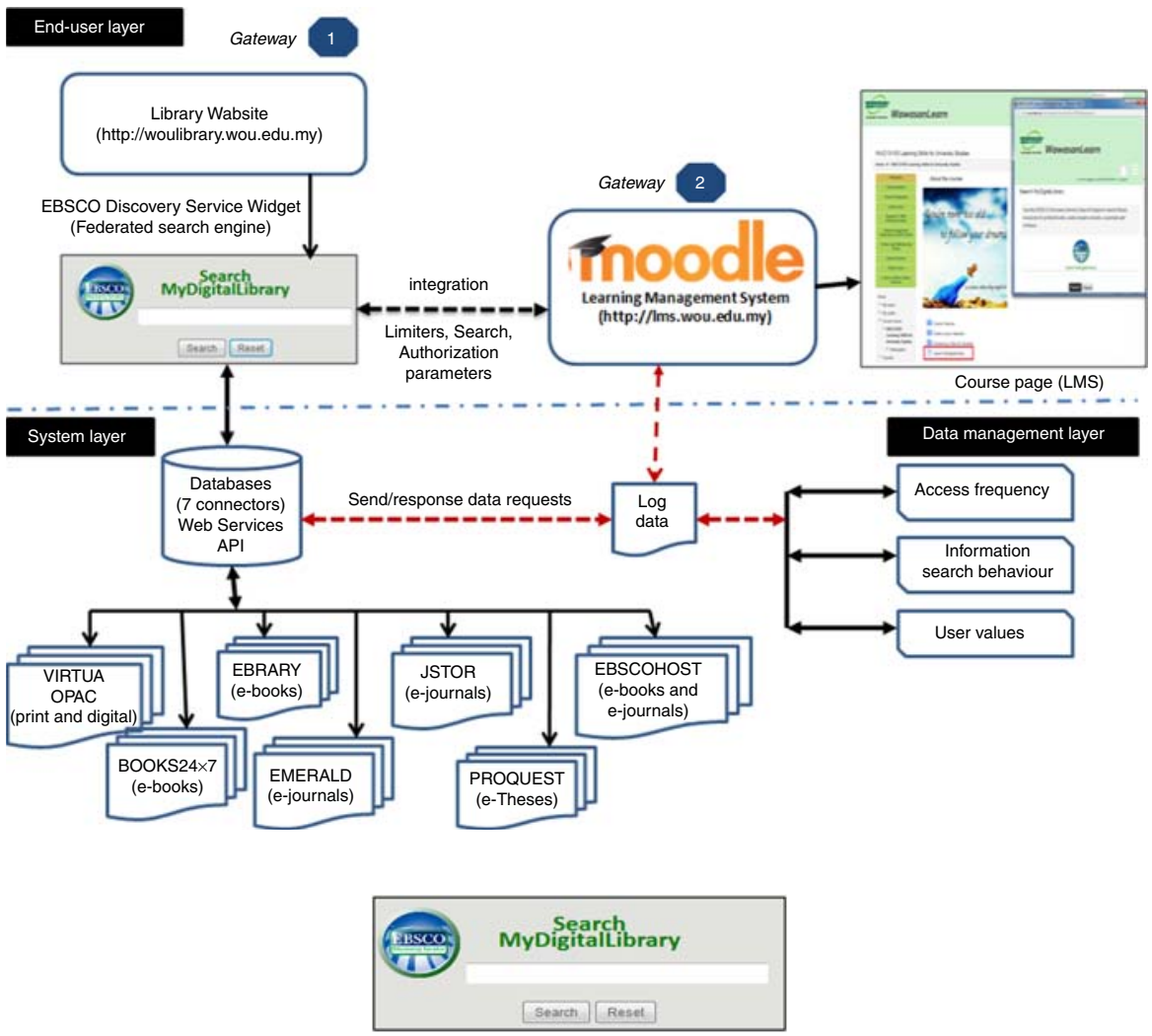

Figure 6. Framework of library resources in LMS

Figure 7 . EDS customized widget 
AAOUJ

12,2

148

\section{System layer}

This layer integrated all the cited seven databases with large holdings stored in each of it and they are being updated regularly by publishers, except for Virtua OPAC which is updated by the librarian. These databases were currently connected to the EDS system where data can be retrieved from the EBSCO search engine widget. For the librarian, these operations were configured on the EBSCOadmin platform where customization is allowed for the required EDS profile (Figure 8).

This section deals with the delivery of electronic resources through the LMS space and the library's EZproxy service, ensuring that authentication is passed from the LMS to the subscribed databases. On the metadata aspect, EDS supports loading of library catalog in MARC21 (machine readable records format) at the frequency set by the librarian via file transfer protocol. It also provides customized ILL forms which has been made available as links on the search results list, detailed citation or journal's table of content page. By selecting the ILL link for a specific record in EDS, patrons are presented with an already filled citation information, and user can submit to the library to source the requested material.

\section{Data management layer}

This layer communicates with the system database layer where it allowed the library administrator to send query requests to generate aggregated log data. The LMS system logs automatically record all users' actions, and library embedded tool usage can also be accessed. In the MOODLE system, from the Administration tab, there is an Activity Report (at the Report option) to track the users' activity in the course as well as the site. Reporting on the total views and last access on any particular resources and activities in the course were made available. MOODLE enabled the course creator and administrator to view course participants and track their usage. Analytics such as IP number, time of access and types of participation were tracked and viewable. These data act as crucial evidence in evincing the activities of the library in meeting the needs of the users, as well as amplifying the value and visibility of the library. Figure 9 presents a screenshot of analytics of users accessing the library space in the LMS.

According to the framework presented in Figure 6's model, the prototype evaluation methodology targets three types of variables, which demonstrate distance learners' library usage patterns. The routinely generated library usage analytics could be linked with information about distance learners therein to understand the following user

Figure 8.

EBSCO administrator interface

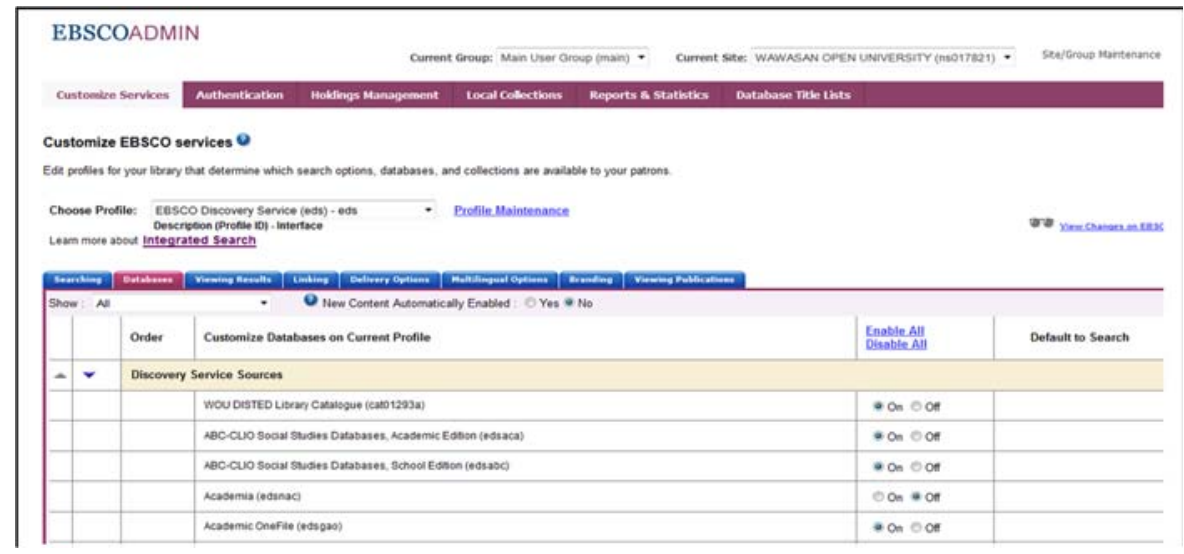

Source: EBSCO (2016b) 


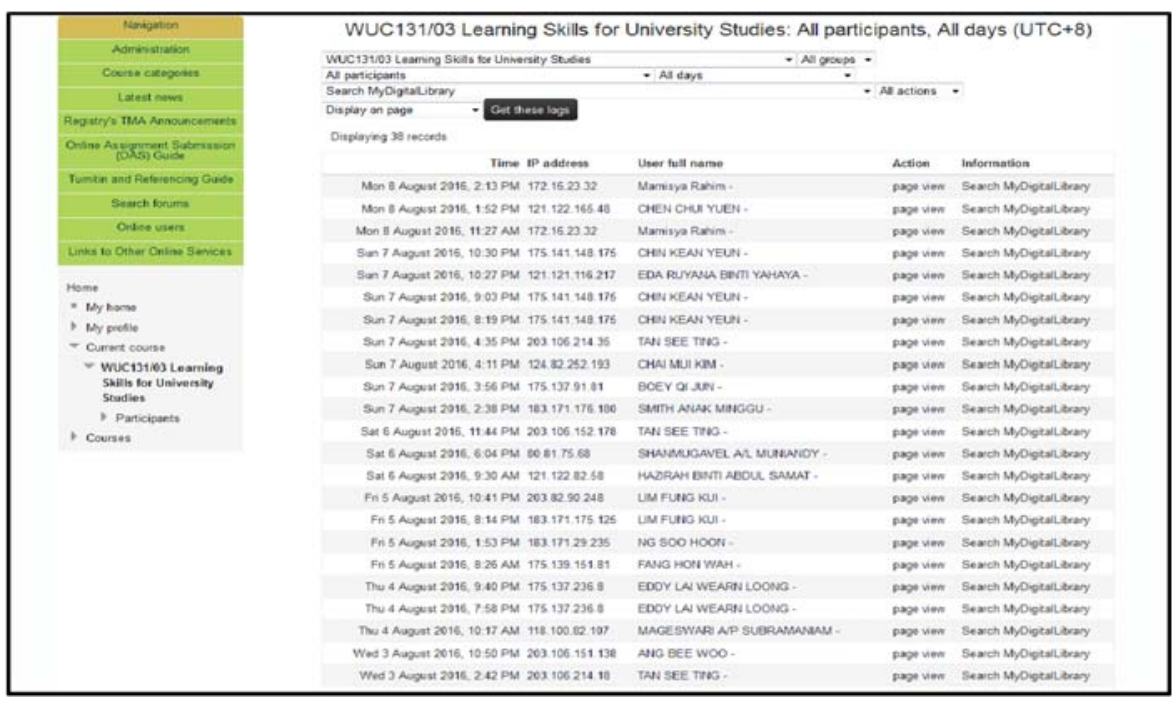

characteristics, i.e. access frequency, information search behavior and user values. Table II provides a brief description of the user characteristics which can be further explored in future research.

Research objective 3: to explore the challenges faced in the integration of the EDS widget into the University's LMS

This section highlights the challenges faced in the integration process.

\section{Identify LMS learning spaces for the library}

It is a common practice in many of the HEIs that the library does not have direct stake in the management of the LMS. In view of this, librarians play an important role in convincing the relevant stakeholders to allow such integration of EDS widget into the learning spaces of the LMS. It is also of equal importance to receive the dedication of associated academic faculties in collaborating in this effort of exploring the technology integration into learning spaces. In the context of this study, the authors explored several micro-level courses where the distance learner numbers were large and also reviewed the log activities to understand the usage patterns of the LMS.

\section{System authentication and integrity}

System authentication and integrity are of important concern for both library and LMS stakeholders to ensure only authorized users can access to the LMS and library resources.

\begin{tabular}{ll}
\hline Variable & Description \\
\hline Access frequency & $\begin{array}{l}\text { Indicates the number and frequency of LMS logins and the amount spent on } \\
\text { accessing library resources }\end{array}$ \\
Information search behavior & $\begin{array}{l}\text { Indicates the information search process and effective utilization of } \\
\text { information obtained } \\
\text { Indicates a meaningful correlation between library resources used and distance } \\
\text { learner's academic performance }\end{array}$
\end{tabular}

\section{EDS widget}

Figure 9.

Analytics of users accessing the library space in LMS 
AAOUJ

12,2
As WOU adopted the single-sign-on approach on all its IT systems, the end users must be able to simply login using their registered login ID at the first-level gateway of access. On the EDS platform, the librarian has to ensure the correct configurations are setup on the library's EZproxy server, and have it tested thoroughly after the integration on the LMS platform. End users must be able to engage in the full access of the system from login to the downloading of full-text content of their search materials without any, or at least minimal system errors.

\section{Application technical challenge}

On the two system integration design methodologies, the amount of technical work involved at the micro-level approach for the LMS administrator was a challenge worth noting in this study. Customization of content in the EDS system platform requires librarian's technical skills and knowledge of all the databases to link up to ensure proper authentication, as well as in ensuring that all links are functioning within the LMS platform. Appropriate programming algorithm of the EDS search engine widget is generated and tested accordingly to fit into the LMS space and function smoothly. The continuous technical support and collaboration between the LMS stakeholder and librarian are very important to ensure the success of the tool interoperability of both integrated systems.

\section{System data mining}

On the data management issue, problems were encountered in maintaining and collating accurate and complete data from various sources or vendors from earlier years. There will be differences among vendors in their definitions of statistical key terms such as sessions, hits, searches and full-text download. Hence, assessment of systems data mining requires thorough planning and compilation of analytics from all relevant stakeholders.

\section{Recommendations for future studies}

Technology is, in fact, more important to the University since it offers distance learning education. Library partnership acts as a way for library to engage in students activities within their community. As the LMS is frequently used in the face-to-face classes and blending learning mode, the features provide a convenient space to make library resources available and accessible.

Future research could investigate on how students perceive the LMS library tool and the effect on distance learners learning engagement to library resources. Both the librarian and the LMS administrator can examine intersection between technology requirements, faculty needs and identifying possible new approaches. The integration can lead to library assessment of effectiveness of distance learners' learning experience in HEIs.

As distance learners access the LMS platform more than the library portal, it is hoped that this integration would lead to a wider scope of information retrieval of library resources. What librarians need to do is to engage more with the distance learners, address the weakness in accessing required resources and bring the library closer to the distance learners.

The library is bound to face challenges in reaching out to their students, especially in the context of distance learning, when there is considerable volume of information available on the internet - not forgetting the fact that the volume of information grows at an exponential rate every day. In attempt to be more persuasive in relating to the concerns of (distance learning) students, effective integration of the EDS widget into the learning spaces of the LMS provide a convenient access to library resources. This measure ensures that the library act as a one-stop database for scholarly information, and simultaneously minimize students' dependency on ineffective Google searching. 
In this study paper, the log data will be utilized and analyzed to determine the usage frequency from the LMS platform and EBSCO statistical tools. Findings from the implementation of the framework also projected potential increase in the usage analytics - particularly in terms of unique (not the usual library user) visitors accessing the library, number of searches (hits), and downloads of full-text resources. This finding established a descriptive correlation to the students' increasing awareness of the library.

It is essential to obtain information on the number of sessions, searches and full-text downloads associated with the library's subscribed databases, as these evidences can be used to support the incur of expenses on the library budget. Jantti and Cox (2013) argue that these analytics will help the library to continually improve and develop its collection, and also to ensure that informed decisions are made.

\section{Conclusion}

This paper discussed the development of a framework that focused on the integration of library into the University's LMS and such integration takes much time and effort to promote the usage in the form of online user trainings and awareness to facilitate visibility. The positive impact of this case study critically depends on the strong collaboration between the library and the LMS stakeholder and existence of a well-integrated plan. The main goal is to create innovative learning landscape as one of the multiple gateways of information access and responsive to distance learners.

WOU Library is constantly looking for innovative ways on how to reach their students more effectively. The expected usage analytics would be the benchmark for the library to renew, or purchase more databases for the University. The authors strongly opine that distance learners and faculty staff will appreciate the integration of EDS on the LMS - a tool that has potential to be a significant part of the LMS facilitating students to optimize information access and retrieval.

\section{References}

Andrew, C. (2013), "Discovery layers and discovery services", Catalogue and Index, No. 170, pp. 2-12, available at: http://shura.shu.ac.uk/7435/1/AC170_article.pdf (accessed January 3, 2017).

Bazillion, R.J. (2001), “Academic libraries in the digital revolution”, Educause Quarterly, No. 1, pp. 51-55.

Behr, M. and LaDell-Thomas, J. (2014), "What do they have that we don't have? Local libraries and distance students: why do students stray and can we get them back?", paper presented at the Sixteenth Distance Library Services Conference Proceedings, Denver, Central Michigan University, Denver, CO, April 23-25, p. 30.

Black, E.L. and Blankenship, B. (2010), "Linking students to library resources through the learning management system", Journal of Library Administration, Vol. 50 Nos 5/6, pp. 458-467.

Breeding, M. (2016), "Data opens new opportunities for libraries", Computers in Libraries, Vol. 36 No. 3, pp. 15-17.

Breeding, M. (2017), “Library systems report 2017”, American Libraries, Vol. 48 No. 5, pp. 22-35.

Choy, F.C. and Goh, S.N. (2016), "A framework for planning academic library spaces”, Library Management, Vol. 37 Nos 1/2, pp. 13-28.

Cooch, M. (2010), Moodle 2.0 First Look: Discover What's New in Moodle 2.0, How the New Features Work, and How it Will Impact You, Packt Publishing Ltd, Olton, Birmingham, 255pp.

Doiron, R. and Asselin, M. (2011), "Exploring a new learning landscape in tertiary education", New Library World, Vol. 112 Nos 5/6, pp. 222-235.

EBSCO (2012), EBSCO’s Complete Discovery Solution: Proposal, EBSCO Publishing, Ipswich, MA, 5pp.

EBSCO (2016a), "EBSCO Discovery Service (EDS) best practices guide - customization. EBSCO Information Service", available at: https://help.ebsco.com/interfaces/EBSCO_Discovery_Service/ EDS_Best_Practices/EDS_Customization_Best_Practices_Guide (accessed January 3, 2017). 
AAOUJ

12,2

EBSCO (2016b), Import Functionality for A Custom Discovery Experience: EBSCO Discovery Service, EBSCO Industries, Inc., Ipswich, MA, available at: www.ebscohost.com/discovery/ customization/widgets (accessed June 28, 2016).

Farkas, M.R. (2015), Libraries in the Learning Management System: Tips and Trends, Instructional Technologies Committee, Association of College and Research Libraries and American Library Association, Chicago, 5pp.

Fatt, C.C. and Su, N.G. (2016), "A framework for planning academic library space", Library Management, Vol. 37 Nos 1/2, pp. 13-28.

Jantti, M. and Cox, B. (2013), "Measuring the value of library resources and student academic performance through relational datasets", Evidence Based Library and Information Practice, Vol. 8 No. 2, pp. 163-171.

Kampa, R.K. (2017), "Bridging the gap: integrating the library into moodle learning management system a study", Library Hi Tech News, Vol. 34 No. 4, pp. 16-21.

Klopfer, E. (2008), Augmented Learning: Research and Design of Mobile Educational Games, MIT Press, Cambridge, p. 251.

Kowalik, E.A. (2015), "Developing a library widget for the campus LMS", Spring/April, available at: https://works.bepress.com/eric_kowalik/9/ (accessed January 3, 2017).

Leeder, C. and Lonn, S. (2014), "Faculty usage of library tools in a learning management system", College \& Research Libraries, Vol. 75 No. 5, pp. 641-663, available at: http://crl.acrl.org/content/ 75/5/641.full.pdf.html (accessed June 10, 2016).

Norbury, K. (2013), The Library has Left the Building, But ..., Campus Technology, Media Inc, Chatsworth, CA, available at: https://campustechnology.com/articles/2013/12/05/the-library-hasleft-the-building-but.aspx (accessed June 28, 2016).

Owen, W. and Michalak, S.C. (2015), "Engine of innovation: building the high performance catalog", Information Technology \& Libraries, Vol. 34 No. 2, pp. 5-18.

Pareek, N. and Gangrade, A. (2016), "Role of the libraries as information resources in globalization", International Journal of Librarianship and Administration, Vol. 7 No. 1, pp. 13-23.

Renauld, J., Britton, S., Wang, D. and Ogihara, M. (2015), "Mining library and university data to understand library use patterns", The Electronic Library, Vol. 33 No. 3, pp. 355-372.

Sarvi, J. and Pillay, H. (2015), Learning Management Systems and Other E-Learning Platform, in Integrated Information and Communication Technology Strategies for Competitive Higher Education in Asia and the Pacific, Asian Development Bank, Manila, 26pp.

Schulte, S.J. (2008), "Integrating information literacy into an online undergraduate nursing informatics course: the librarian's role in the design and teaching of the course", Medical Reference Services Quarterly, Vol. 27 No. 2, pp. 158-172.

Seal, R.A. (2015), "Library spaces in the 21st century: meeting the challenges of user needs for information, technology, and expertise", Library Management, Vol. 36 Nos 8/9, pp. 558-569.

Shank, J.D. and Dewald, N.H. (2003), "Establishing our presence in courseware: adding library services to the virtual classroom", Information Technology and Libraries, Vol. 22 No. 1, pp. $38-43$.

Tumbleson, B.E. and Burke, J.J. (2013), Embedding Librarianship in Learning Management Systems: A How-to-do-it Manual for Librarians, Neal-Schuman, Chicago, IL, p. 148, available at: http://eds.a.ebscohost.com/eds/ebookviewer/ebook/bmxlYmtfXzcwNTgyM19fQU41?sid =92874182-9a6a-47ba-a7d5-199bc8bbdd18@sessionmgr4007\&vid=0\&format=EB\&rid=1 (accessed September 11, 2017).

Vaughan, J. (2011), EBSCO Discovery Service, ALA TechSource, 1, available at: https:/journals.ala.org/ index.php/ltr/article/view/4384/5073 (accessed January 3, 2017).

Vighnarajah and Santhiram, R. (2014), "Characterizing key features of student isolation in distance education", unpublished IRI Research final report, Institute for Research and Innovation, Wawasan Open University, Penang, p. 25. 
Vighnarajah, S., Norhasni, A.A. and Ooi, S.L. (2015), "Profiling information seeking behaviour of distance learning students in Wawasan Open University, Penang, Wawasan Open University", paper presented at the 29th Annual Conference of the Asian Association of Open Universities, Kuala Lumpur, November 30-December 2, p. 13.

Wikipedia (2016), EZproxy, Wikimedia Foundation, Inc., San Francisco, CA, available at: https:/en. wikipedia.org/wiki/EZproxy (accessed January 3, 2017).

Corresponding author

Bee Leng Chew can be contacted at: blchew@wou.edu.my

For instructions on how to order reprints of this article, please visit our website: 